\title{
PENGARUH DISIPLIN KERJA DAN PELAYANAN PEGAWAI TERHADAP KEPUASAN MASYARAKAT PADA KANTOR KELURAHAN KLAMANA KOTA SORONG
}

\author{
1Yulius Frits Momot, ${ }^{2 *}$ Mitta Muthia Wangsi, ${ }^{3}$ Kamaluddin , ${ }^{4}$ Ahmad Jamil \\ Universitas Muhammadiyah Sorong, Papua Barat, Indonesia \\ ”mithamuthia@gmail.com
}

\begin{abstract}
Abstrak
Penelitian ini bertujuan untuk mengetahui pengaruh disiplin kerja dan pengaruh pelayanan pegawai terhadap kepuasan masyarakat di Kantor Kelurahan Klamana Kota Sorong. Penelitian ini menggunakan metode deskriptif dan korelasi dengan menggunakan pendekatan kuantitatif. Teknik analisis data menggunakan regresi linear berganda. Hasil penelitian menunjukkan bahwa: Disiplin kerja berpengaruh positif dan signifikan terhadap keputusan pembelian, hal ini dibuktikan berdasarkan nilai signifikan sebesar $(0,002<0,05)$, nilai t-hitung lebih besar dari t-tabel $(3,211>2,002)$, dan nilai koefisien regresi sebesar 0,408. Pelayanan Pegawai berpengaruh positif dan signifikan terhadap keputusan pembelian, hal ini dibuktikan berdasarkan nilai signifikan sebesar $(0,000<0,05)$, nilai $\mathrm{t}$ hitung lebih besar dari t-tabel $(3,911>2,002)$, dan nilai koefisien regresi sebesar 0,337.
\end{abstract}

Kata Kunci: Disiplin Kerja, Pelayanan Pegawai dan Kepuasan Masyarakat

\section{Abstract}

This research aims to find out the influence of work discipline and the influence of employee service on community satisfaction in the Klamana Village Office of Sorong City. The study used descriptive and correlation methods using quantitative approaches. Data analysis techniques use multiple linear regressions. The results showed that: The discipline of work had a positive and significant effect on purchasing decisions, this was proven based on a significant value of $(0.002<0.05)$, a t-count value greater than the $t$-table $(3,211>2,002)$, and a regression coefficient value of 0.408 . Employee service has a positive and significant effect on purchasing decisions, this is evidenced based on significant values $(0.000<0.05)$, $t$-calculated values greater than $t$-tables $(3,911$ $>2,002)$, and regression coefficient values of 0.337 .

Keywords: Work Discipline, Staffing Services and Community Satisfaction

\section{PENDAHULUAN}

Suatu organisasi merupakan wadah atau tempat yang digunakan beberapa orang untuk melakukan kerjasama. Kantor Kelurahan Klamana merupakan salah satu organisasi pemerintahan yang bertugas memberikan kepuasan pelayanan kepada masyarakat tingkat pertama setelah RT. Organisasi akan berkembang dengan baik tergantung pada kualitas pelayanan sumberdaya manusia (SDM) yang tercermin dari setiap efektivitas dan efisiensi kegiatan yang dilakukan.

Kedudukan dan peranan Pegawai Negeri Sipil sebagai unsur aparatur Negara yang bertugas sebagai abdi masyarakat harus menyelenggarakan pelayanan secara adil kepada masyarakat dengan dilandasi kesetiaan dan ketaatan kepada Pancasila dan Undang-Undang Dasar 1945. Untuk dapat melaksanakan tugas dengan baik, maka pembinaan pegawai diarahkan untuk meningkatkan kualitas sumber daya manusia agar memiliki sikap dan perilaku yang berintikan pengabdian, kejujuran, tanggungjawab, disiplin serta wibawa sehingga dapat memberikan pelayanan sesuai tuntutan perkembangan masyarakat.

Aktivitas pelayanan dalam suatu organisasi atau lembaga akan sangat berperan dalam kelancaran kegiatan organisasi. Pelayanan dalam organisasi khususnya kantor dituntut untuk cepat dan tepat. Hal tersebut merupakan kewajiban 
yang harus dilakukan. Bagi organisasi publik, pelayanan yang baik tercermin dari setiap efektivitas dan efisiensi kegiatan yang dilakukan. Semakin cepat dan akurat pelayanan yang diberikan maka kualitas pelayanan akan semakin baik. Kantor akan memberikan pelayanan yang baik agar kepuasan pelanggan dapat tercapai. Pelaksanaan kegiatan pelayanan kantor diarahkan kepada pencapaian efisiensi dan efektivitas kerja. Efisiensi berkaitan caracara yang digunakan untuk mencapai tujuan yang telah ditentukan. Cara tersebut dapat berupa cara yang paling cepat maupun cara yang paling lama tetapi pencapaian tujuannya sama sedangkan efektivitas berkaitan dengan pencapaian tujuan yang telah ditentukan. Kepuasan pelanggan akan tercapai jika pelayanan yang diberikan sesuai dengan apa yang diharapkan.

Kantor Kelurahan Klamana dalam memberikan pelayanan kepada masyarakat sejauh ini belum maksimal. Berdasarkan hasil pengamatan pada tanggal 11-13 Januari 2021 terkait disiplin kerja, masih ada beberapa pegawai yang belum menerapkan disiplin dan pelayanan yang baik dalam bekerja. Hal tersebut, terlihat dari kehadiran pegawai yang datang belum tepat waktu sehingga kegiatan pelayanan terganggu dan menyulitkan masyarakat yang mempunyai kepentingan dengan pegawai tersebut. Jam kerja pegawai Kantor Kelurahan Klamana pukul 08.00- 16.00 WIT akan tetapi, pada pukul 09.00 - 10.00 WIT pegawai Kantor Kelurahan Klamana baru datang untuk bekerja dan pada pukul 13.00 WIT pegawai sudah pulang lebih awal dari jam operasional. Hal ini terjadi karena di Kantor Kelurahan Klamana tidak ada peraturan yang tertulis, sehingga dari kenyataan tersebut mendukung pegawai untuk tidak disiplin dan pelayanan diberikan berdasarkan keinginan serta kebudayaan pegawai itu sendiri.

Berdasarkan permasalahan di atas, diketahui bahwa pegawai Kantor Kelurahan Klamana belum memberikan kualitas pelayanan yang baik kepada masyarakat. Maka dilakukan sebuah kajian mengenai "Pengaruh Disiplin Kerja dan Pelayanan Pegawai Terhadap Kepuasan Masyarakat Pada Kantor Kelurahan Klamana Kota Sorong.

\section{METODE}

Jenis penelitian yang dipakai adalah asosiatif kausal, dimana tujuannya adalah untuk mengetahui pengaruh antara variabel bebas terhadap variabel terikat baik parsial maupun simultan. Populasi dalam penelitian ini berjumlah 60 responden di Kantor Kelurahan Klamana di Sorong, Papua Barat. Sampel dalam penelitian ini berjumlah 60 responden.

\section{HASIL PENELITIAN DAN PEMBAHASAN}

a. Uji Validitas

Validitas adalah ketepatan atau kecermatan suatu instrument dalam mengukur apa yang ingin diukur.

Tabel 1. Hasil Uji Validitas

\begin{tabular}{|c|c|c|c|}
\hline KODE ITEM & $\begin{array}{c}\mathrm{R} \\
\text { Hitung }\end{array}$ & $\begin{array}{c}\mathrm{R} \\
\text { Tabel }\end{array}$ & Keterangan \\
\hline KD1 &, $710^{* *}$ & 0,254 & Valid \\
\hline KD2 &, $540^{* *}$ & 0,254 & Valid \\
\hline KD3 &, $373^{* *}$ & 0,254 & Valid \\
\hline KD4 &, $400^{* *}$ & 0,254 & Valid \\
\hline KD5 &, $455^{* *}$ & 0,254 & Valid \\
\hline KD6 &, $474^{* *}$ & 0,254 & Valid \\
\hline KD7 &, $605^{* *}$ & 0,254 & Valid \\
\hline KD8 &, $563^{* *}$ & 0,254 & Valid \\
\hline P1 &, $573^{* *}$ & 0254 & Valid \\
\hline P2 &, $625^{* *}$ & 0,254 & Valid \\
\hline P3 &, $546^{* *}$ & 0,254 & Valid \\
\hline P4 &, $590^{* *}$ & 0,254 & Valid \\
\hline P5 &, $516^{* *}$ & 0,254 & Valid \\
\hline P6 &, $579^{* *}$ & 0,254 & Valid \\
\hline P7 &, $576^{* *}$ & 0,254 & Valid \\
\hline P8 &, $675^{* *}$ & 0,254 & Valid \\
\hline P9 &, $391^{* *}$ & 0,254 & Valid \\
\hline P10 &, $493^{* *}$ & 0,254 & Valid \\
\hline KM1 &, $639^{* *}$ & 0,254 & Valid \\
\hline KM2 &, $268^{*}$ & 0,254 & Valid \\
\hline KM3 &, $657^{* *}$ & 0,254 & Valid \\
\hline KM4 &, $402^{* *}$ & 0,254 & Valid \\
\hline KM5 &, $587^{* *}$ & 0,254 & Valid \\
\hline KM6 &, $550^{* *}$ & 0,254 & Valid \\
\hline KM7 &, $292^{*}$ & 0,254 & Valid \\
\hline KM8 &, $592^{* *}$ & 0,254 & Valid \\
\hline
\end{tabular}


Berdasarkan tabel 1 di atas memiliki nilai $r$ hitung $>0,254$ nilai $r$ tabel, maka data valid dan dapat dilanjutkan dalam uji reliabilitas.

\section{b. Uji Rehabilitas}

Untuk menentukan keandalan suatu pertanyaan digunakan program komputer SPSS, hingga diperoleh nilai Cronbach's Alpha untuk tiap variabel penelitian.

Tabel 2. Hasil Uji Reliabilitas

\begin{tabular}{|l|c|c|c|}
\hline \multicolumn{1}{|c|}{ Variabel } & $\begin{array}{c}\text { Cronbac } \\
h^{\prime} \text { s } \\
\text { Alpha }\end{array}$ & $\begin{array}{c}\text { Nilai } \\
\text { Krisis } \\
\text { Cronbac } \\
h^{\prime} \text { s } \\
\text { Alpha }\end{array}$ & $\begin{array}{c}\text { Keteran } \\
\text { gan }\end{array}$ \\
\hline $\begin{array}{l}\text { Disiplin Kerja } \\
\text { (X1), } \\
\text { PelayananPeg } \\
\text { awai (X2), } \\
\text { dan } \\
\text { Kepuasan } \\
\begin{array}{l}\text { Masyarakat } \\
\text { (Y). }\end{array}\end{array}$ & 0,897 & 0,60 & Reliabel \\
\hline
\end{tabular}

Nilai cronbach's alpha pada variabel menunjukan intrumen yang digunakan reliabel atau memberikan hasil yang relatif konstan jika dihitung berulangulang. Hal ini ditunjukan dengan hasil dengan hasil koefisien reliabilitas 0,897 > 0.60 .

\section{c. Uji Normalitas}

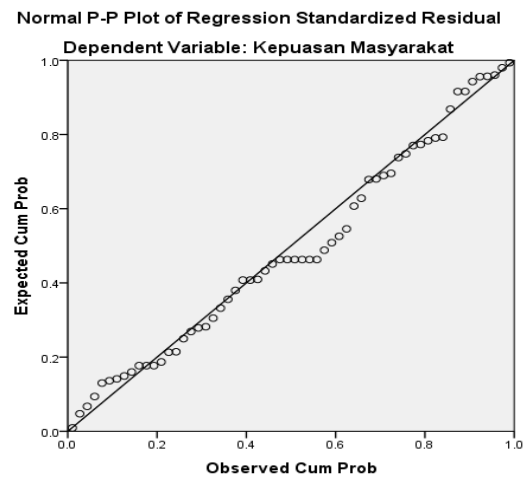

Gambar 1. Uji Normalitas

Pada garis normal P-P Plot of regression standardized residual terlihat titik-titik menyebar di sekitar garis diagonal, serta penyebarannya mengikuti arah garis diagonal, maka dapat disimpulkan bahwa data terdistribusi normal.

\section{d. Uji Linearitas}

Tabel 3. Hasil Uji Linearitas

ANOVA Table

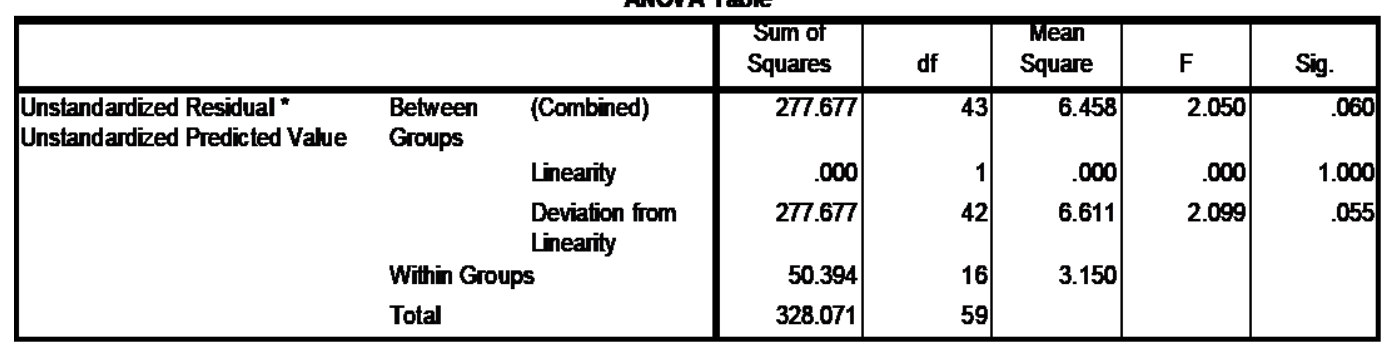

Dilihat bahwa nilai Sig Linearity $1,000>0,05$ (taraf signifikansi). Kesimpulan bahwa kedua variabel independen yaitu disiplin kerja dan

\section{e. Uji Heteroskedastisitas}

pelayanan pegawai memiliki hubungan yang linear terhadap variabel dependen yaitu kepuasan masyarakat.

Tabel 4. Hasil Uji Heteroskedastisitas

Coefiicients ${ }^{a}$

\begin{tabular}{|c|c|c|c|c|c|}
\hline \multirow[b]{2}{*}{ Model } & \multicolumn{2}{|c|}{$\begin{array}{l}\text { Unstandardized } \\
\text { Coefficients }\end{array}$} & \multirow{2}{*}{$\begin{array}{c}\begin{array}{c}\text { Standardized } \\
\text { Coefficients }\end{array} \\
\text { Beta }\end{array}$} & \multirow[b]{2}{*}{$\mathbf{t}$} & \multirow[b]{2}{*}{ Sig. } \\
\hline & $\bar{B}$ & Std. Eтror & & & \\
\hline (Constant) & 4.809 & 1.668 & & 2.883 & .006 \\
\hline Disiplin Kerja & -.110 & .075 & -.252 & -1.452 & .152 \\
\hline Pelayanan Pegawai & .001 & .051 & .005 & .029 & .977 \\
\hline
\end{tabular}


Dapat dilihat bahwa nilai Sig variabel disiplin kerja sebesar 0,152 dan pelayanan pegawai sebesar 0,977. kesimpulan masing-masing variabel independen memiliki nilai Sig lebih besar dari > 0,05 maka tidak ditemukan adanya masalah heterokedastisitas.

\section{f. Uji Multikolinearitas}

Tabel 5. Hasil Uji Multikolinearitas

Coefficients ${ }^{a}$

\begin{tabular}{|c|c|c|c|c|c|c|c|c|}
\hline \multirow[b]{2}{*}{ Mode } & & \multicolumn{2}{|c|}{$\begin{array}{l}\text { Unstandardized } \\
\text { Coefficients }\end{array}$} & \multirow{2}{*}{$\begin{array}{c}\begin{array}{c}\text { Standardized } \\
\text { Coefficients }\end{array} \\
\text { Beta }\end{array}$} & \multirow[b]{2}{*}{$t$} & \multirow[b]{2}{*}{ Sig. } & \multicolumn{2}{|c|}{ Colnearity Statistics } \\
\hline & & $\bar{B}$ & Std. Error & & & & Tolerance & VIF \\
\hline \multirow[t]{3}{*}{1} & (Constant) & & 2.808 & & 2.607 & .012 & & \\
\hline & Disipln Kerja & & .127 & .374 & 3.211 & .002 & .546 & 1.831 \\
\hline & Pelayanan Pegawai & & .086 & .456 & 3.911 & .000 & .546 & 1.831 \\
\hline
\end{tabular}

Dapat dilihat bahwa nilai Tolerance disiplin kerja dan pelayanan pegawai sebesar 0,546 yang berarti $>0,1$ dan nilai Variance Inflation Factor (VIF) sebesar 1,831 yang berarti $<10$, maka analisis ini dapat di simpulkan bahwa tidak terjadi gejala multikolinearitas dalam model regresi.

Tabel 6. Hasil AnalisisRegresi Linier Berganda

Coefficients"

\begin{tabular}{|c|c|c|c|c|c|c|}
\hline \multirow[b]{2}{*}{ Model } & & \multicolumn{2}{|c|}{$\begin{array}{l}\text { Unstandardized } \\
\text { Coefficients }\end{array}$} & \multirow{2}{*}{$\begin{array}{c}\begin{array}{c}\text { Standardized } \\
\text { Coefficients }\end{array} \\
\text { Beta }\end{array}$} & \multirow[b]{2}{*}{$\mathbf{t}$} & \multirow[b]{2}{*}{ Sig. } \\
\hline & & B & Std. Error & & & \\
\hline \multirow[t]{3}{*}{1} & (Constant) & 7.321 & 2.808 & & 2.607 & .012 \\
\hline & Disiplin Kerja & .408 & .127 & .374 & 3.211 & .002 \\
\hline & Pelayanan Pegawai & .337 & .086 & .456 & 3.911 & .000 \\
\hline
\end{tabular}

a. Dependent Variable: Kepuasan Masyarakat

Maka dapat disajikan persamaan regresi yaitu sebagai berikut:

$\mathrm{Y}=\mathrm{a}+\mathrm{b} 1 \mathrm{X} 1+\mathrm{b} 2 \mathrm{X} 2+\mathrm{e}$

$Y=7,321+0,408 X 1+0,337 X 2$

Persamaan tersebut menunjukkan bahwa jika:

a) Nilai koefisien $X 1$ sebesar 0,408 artinya apabila Disiplin Kerja (X1) meningkat 1 poin, maka nilai Kepuasan Masyarakat (Y) akan meningkat 0,408 .

b) Nilai koefisien $\mathrm{X} 2$ sebesar 0,337 artinya apabila Pelayanan Pegawai (X2) meningkat 1 poin, maka nilai Kepuasan Masyarakat (Y) akan meningkat 0,337 .

\section{g. Analisis Regresi Linier Berganda}

Analisis regresi linier berganda dimaksud untuk menguji seberapa besar pengaruh disiplin kerja, pelayanan pegawai terhadap kepuasan masyarakat pada Kantor Kelurahan Klamana Kota Sorong. 
Tabel 7. Hasil Uji T

Coefficients"

\begin{tabular}{|c|c|c|c|c|c|c|}
\hline \multirow{2}{*}{\multicolumn{2}{|c|}{ Model }} & \multicolumn{2}{|c|}{$\begin{array}{l}\text { Unstandardized } \\
\text { Coefficients }\end{array}$} & \multirow{2}{*}{$\begin{array}{c}\begin{array}{c}\text { Standardized } \\
\text { Coefficients }\end{array} \\
\text { Beta }\end{array}$} & \multirow[b]{2}{*}{$\mathrm{t}$} & \multirow[b]{2}{*}{ Sig. } \\
\hline & & B & Std. Error & & & \\
\hline \multirow[t]{3}{*}{1} & (Constant) & 7.321 & 2.808 & & 2.607 & .012 \\
\hline & Disiplin Kerja & .408 & .127 & .374 & 3.211 & .002 \\
\hline & Pelayanan Pegawai & .337 & .086 & .456 & 3.911 & .000 \\
\hline
\end{tabular}

a. Dependent Variable: Kepuasan Masyarakat

Nilai $\mathrm{t}$ tabel $\mathrm{n}-\mathrm{k}-1=60-2-1=57$ adalah sebesar 2,002 dengan taraf signifikansi 0,05 , untuk variabel disiplin kerja nilai $t$ hitung sebesar 3,211 $>2,002$ dan tingkat Sig 0,002<0,05. Berdasarkan kriteria pengujiannya $t$ hitung $>t$ tabel, maka Ha diterima dan Ho ditolak dan tingkat signifikannya adalah $<0,05$. Yang dapat disimpulkan bahwa Hipotesis H1.1 diterima dinyatakan Ada Pengaruh Positif dan Signifikan Disiplin Kerja (X1) Terhadap Kepuasan Masyarakat (Y).
Variabel pelayanan pegawai nilai $t$ hitung sebesar 3,911 > 2,002 dan tingkat Sig 0,000 < 0,05. Berdasarkan kriteria pengujiannya thitung $>\mathrm{t}$ tabel, maka $\mathrm{Ha}$ diterima dan Ho ditolak dan tingkat signifikannya adalah $<0,05$. Yang dapat disimpulkan bahwa Hipotesis H1.2 diterima dinyatakan Ada PengaruhPositif dan Signifikan Pelayanan Pegawai (X2) Terhadap Kepuasan Masyarakat (Y).

i. Analisis Koefisien Determinasi $\left(\mathbf{R}^{2}\right)$

Tabel 8. Koefisien Determinasi $\left(\mathrm{R}^{2}\right)$

\begin{tabular}{|c|c|c|c|c|}
\hline \multicolumn{5}{|c|}{ Model Summary } \\
\hline Model & $\mathbf{R}$ & R Square & $\begin{array}{l}\text { Adjusted R } \\
\text { Square }\end{array}$ & $\begin{array}{c}\text { std. Error of the } \\
\text { Estimate }\end{array}$ \\
\hline 1 & $.760^{a}$ & .577 & .562 & 2.399 \\
\hline
\end{tabular}

Koefisien determinasi pada nilai Adjusted $R$ Square sebesar 0.562, di mana $56.2 \%$ kepuasan masyarakat dapat dijelaskan oleh variabel independen yaitu disiplin kerja dan pelayanan pegawai. Sedangkan $43.8 \%$ dapat dijelaskan dengan variabel lain yang tidak diangkat dalam penelitian ini.

\section{PEMBAHASAN HASIL PENELITIAN}

a. Pengaruh Disiplin Kerja Terhadap Kepuasan Masyarakat

Berdasarkan hasil data yang diperoleh menunjukkan Disiplin Kerja berpengaruh positif dan signifikan dengan nilai $t$ hitung sebesar 3,211 > 2,002 dan tingkat Sig 0,002 <0,05, maka hipotesis H1.1 diterima. Menunjukan bahwa Ada Pengaruh Positif dan Signifikan Disiplin Kerja Terhadap Kepuasan Masyarakat Pada Kantor
Kelurahan Klamana Kota Sorong dan nilai koefisien regresi 0,408 (40.8\%).

b. Pengaruh Pelayanan Pegawai Terhadap Kepuasan Masyarakat

Berdasarkan hasil data yang diperoleh menunjukkan Pelayanan Pegawai berpengaruh positif dan signifikan dengan nilai $\mathrm{t}$ hitung sebesar 3,911 > 2,002 dan tingkat Sig 0,000<0,05, maka hipotesis H1.2 diterima. Menunjukan bahwa Ada Pengaruh Positif dan Signifikan Pelayanan Pegawai Terhadap Kepuasan Masyarakat Pada Kantor Kelurahan Klamana Kota Sorong dan nilai koefisien regresi $0,337(33.7 \%)$.

\section{PENUTUP}

\section{Kesimpulan}

a. Hasil penelitian terkait disiplin hasil analisa data bahwa disiplin kerja 
memperoleh nilai koefisien regresi sebesar 0,408 (40.8\%), yang berarti permasalahan di lapangan disiplin kerja menerangkan $40.8 \%$ dan berpengaruh positif dan signifikan terhadap kepuasan masyarakat yang dibuktikan berdasarkan nilai signifikan sebesar $0,002<0,05$ dan nilai $t$ hitung sebesar $3,211>2,002$. Hal ini berarti, disiplin kerja pegawai berpengaruh terhadap kepuasan masyarakat secara langsung.

b. Hasil analisa data yang diperoleh nilai koefisien regresi sebesar 0,337 (33.7\%), yang berarti permasalahan di lapangan pelayanan pegawai menerangkan $33.7 \%$ dan berpengaruh positif dan signifikan terhadap kepuasan masyarakat yang di buktikan berdasarkan nilai signifikan sebesar $0,000<0,05$ dan nilai $t$ hitung sebesar 3,911 >2,002.

\section{Saran}

Saran yang penulis rangkum dari hasil masukan dari masyarakat, bahwa Ibu lurah selaku atasan di Kelurahan Klamana Kota Sorong agar membuat peraturan tertulis supaya semua pegawai menerapkan, mentaati dan memperbaiki disiplin waktunya dalam bekerja sehingga masyarakat mendapatkan pelayanan yang tepat, cepat dan memuaskan.

\section{DAFTAR PUSTAKA}

Affandi, A., et al.. (2020). Optimization of MSMEs Empowerment in Facing Competition in the Global Market during the COVID-19 Pandemic Time. Systematic Reviews in Pharmacy, 11(11), 1506-1515.

Agus B.S dkk. 2013. Pengaruh Kedisiplinan Dan Ketangapan Terhadap Kepuasan Pelangan Dengan Kualitas Pelayanan Sebagai Variabel Intervening (Studi Pada Hotel Di Kabupaten Semarang).

Arikunto S. 1998. Prosedur Penelitian Suatu Pendekatan Praktek. Cetakan ke-11. Jakarta: PT Rineka Cipta. Hlm: 67, 256.

Astia Tika. 2015. Pengaruh Kualitas Pelayanan Terhadap Kepuasan Masyarakat Pada Kantor Camat Tanjung pinang Timur.
Skripsi Univesrsitas Maritim Raja Ali Haji Tanjung pinang.

Dessler, Gary. 1992. Manajemen Sumber-daya Manusia, Jakarta: Prenhallindo.

Eulin Karlina, dkk. 2019. Pengaruh Kualitas Pelayanan dan Kedisiplinan Pegawai Terhadap Kepuasan Masyarakat Pada Kantor Lurah Klender Jakarta Timur. Skripsi Universitas Bina Sarana Infomatika.

Luluh Endah Khariri. 2019. Pengaruh Kualitas Pelayanan, Disiplin Kerja, Komunikasi Interpersonal dan Fasilitas Pelayanan Terhadap Kepuasan Masyarakat Di Dinas Kependudukan dan Pencatatan Sipil Kabupaten Pemalang. Skripsi Universitas Negeri Semarang. Mangkunegara, A. P. 2000. “Kinerja (prestasi kerja)". Bandung: PT Remaja Rosdakarya.

Muslimat, A., et al.. (2020). Effect Of Organizational Commitment On The Sustainability Performance Of Indonesian Industries. PalArch's Journal of Archaeology of Egypt/Egyptology, 17(6), 8330-8347.

Narmod H dkk. 2016. Pengaruh Motivasi dan Disiplin Terhadap Kinerja Pegawai Badan Kepegawaian Daerah Kabupaten Wonogiri. Jurnal Imliah. Kabupaten Wonogiri

Nurjaya, N., et al.. (2020). The Effect of Work Stress and Work Conflict on Employees Turnover Intention In Middle Small Micro Enterprises (MSMEs) In South Tangerang Region. International Journal of Educational Administration, Management, and Leadership, 51-62.

Rahayu.A. 2005. Pengaruh Kualitas Pelayanan Dan Semangat Kerja Pegawai Terhadap Kepuasan Masyarakat Yang Di Layani Pada Kantor Kecamatan Rembang Kabupaten Rembang. Skripsi UNNES.

Rawi, R. D. P. (2017). Analisis Hubungan Motivasi Terhadap Kinerja Pegawai (Studi Kasus Pada Kantor Kecamatan Ruing Kabupaten Ngada Ntt). Jurnal Noken: Ilmu-Ilmu Sosial, 2(2), 15-28.

Rika $\begin{gathered}\text { Ayu } \\ \text { PengaruhKompetensiPegawai, }\end{gathered}$ 
DisiplinPegawai dan

KeadilanPelayananTerhadapKepuasan

Masyarakat Di Kantor

KecamatanUngaran Barat Kabupaten

Semarang. Skripsi Universitas Negeri Semarang.

Safitriani

PengaruhDisiplinKerjaTerhadap Kinerja Pegawai Pada Dinas Pendidikan Pemuda dan Olaraga Di Kab. Jeneponto. Skripsi UIN Alaudin Makassar.

Suwanto, S., et al. (2021). Pengaruh Motivasi Dan Pengalaman Kerja Terhadap Produktivitas Karyawan Pada Happy Restaurant Di Bandung. Jurnal Ekonomi Efektif, 3(4), 546-554.
Tjiptono, F. (2012). Service Management: MewujudkanPelayanan Prima. Yogyakarta: Andi Offset.

Tjiptono, F. (2014). Pemasaran Jasa - Prinsip, Penerapan, dan Penelitian. Yogyakarta: Andi Offset.

Widya

V.(2018).PengaruhKualitasPelayananPu blik Dan DisiplinKerja Pegawai Terhadap Kepuasan Masyarakat Di Kantor Balai Desa Rowosari Kecamatan Ulujami Kabupaten Pemalang.Skripsi UNY. Yunanto Yogi (2017). AnalisisPengaruhKualitasPelayanan Dan DisiplinKerjaKaryawanTerhadapKepuas anPasien Askes Di PT Askeks Kediri. TesisDosen Universitas Kediri. 